\title{
Comment to: “Predictors of ischemic bowel in patients with incarcerated hernias"
}

\author{
M. Tez ${ }^{1}$
}

Received: 31 January 2019 / Accepted: 11 March 2019 / Published online: 16 March 2019

๑) Springer-Verlag France SAS, part of Springer Nature 2019

Dear Sir,

I read the manuscript entitled "Predictors of ischemic bowel in patients with incarcerated hernias [1]" with interest. But, I think that there is a major flaw in the presented article.

Multivariate analysis is a tool for determining the relative contributions of different causes to a single event. A common problem in the analysis is the selection of those independent variables in a multivariate analysis that might influence the outcome variable. In most cases, researchers are cognizant of the effects of leaving out an important variable from the model, so they will collect data on any variable they think might be important. With moderate numbers of variables, fitting all possible models is not computationally feasible. The most popular algorithms are stepwise methods. Stepwise methods are easy to compute and, therefore, are extremely popular. There is no agreement on the best criterion for the addition and deletion of variables in a stepwise procedure. Ideally, such a threshold will exclude noise variables and include relevant ones. There is no consensus on what that level should be, and suggestions range from using a $p$ value of 0.01-0.50. Different strategies will have important effects on the final model selected [2,3].

It is not easy to understand why do the authors choice skin changes and hyponatremia as independent variables for multivariate analyses? Other variables such as WBC count $(p=0.001)$, bicarbonate level $(p=0.04)$, and creatinine level $(p=0.005)$ were not included the multivariate analysis in the study: I want to ask: Why?
In conclusion, due to the major flaw, results of the study must be interpreted cautiously.

\section{Compliance with ethical standards}

Conflict of interest There is no conflict of interest to declare.

Ethical approval For this type of study, Ethical approval was not necessary.

Human and animal rights This article does not contain any studies directly involving human participants.

Inform consent For this type of study, formal consent was not necessary.

\section{References}

1. Keeley J, Kaji A, Kim D, Putnam B, Neville A (2019) Predictors of ischemic bowel in patients with incarcerated hernias. Hernia. https://doi.org/10.1007/s10029-019-01884-1

2. Zellner D, Keller F, Zellner GE (2004) Variable selection in logistic regression models. Commun Stat Simul Comput 33(3):787-805

3. Thompson WR (2009) Variable selection of correlated predictors in logistic regression: investigating the diet-heart hypothesis. The Florida State University, Tallahassee

Publisher's Note Springer Nature remains neutral with regard to jurisdictional claims in published maps and institutional affiliations.
M. Tez

mesuttez@yahoo.com

1 Department of General Surgery, Ankara Numune Teaching Hospital, Sihhiye, Ankara, Turkey 